\title{
ТРЕБОВАНИЯ К СИСТЕМАМ КОМПЕТЕНЦИЙ И ПРИНЦИПЫ ИХ РАЗРАБОТКИ ДЛЯ МАЛЫХ ИННОВАЦИОННЫХ ПРЕДПРИЯТИЙ
}

\author{
(c) 2021 Синявина Мария Павловна \\ ассистент \\ Санкт-Петербургский политехнический университет Петра Великого, Россия, Санкт-Петербург \\ E-mail:sinmp@inbox.ru \\ (C) 2021 Бурмистров Андрей Николаевич \\ кандидат экономических наук, доцент \\ Санкт-Петербургский политехнический университет Петра Великого, Россия, Санкт-Петербург \\ E-mail: bur-a-n@mail.ru

\section{(c) 2021 Мухина Екатерина Дмитриевна} \\ бакалавр по направлению «Управление персоналом» (выпускница) \\ Санкт-Петербургский политехнический университет Петра Великого, Россия, Санкт-Петербург \\ E-mail: mukhinakate1@yandex.ru
}

Проведен анализ систем компетенций, представленных в современной научной литературе и нормативных документах, с точки зрения возможности их применения для повышения качества управления проектной деятельностью на малых инновационных предприятиях (МИП). Выявлены существенные ограничения возможности применения существующих систем для целей управления проектами на МИП, обусловленные их сложностью и высоким уровнем обобщенности. Обоснована необходимость разработки системы компетенций для участников команд инновационных проектов МИП, учитывающей особенности осуществления проектной деятельности этой категории предприятий. Выявлены ключевые особенности управления проектами на малых инновационных предприятиях. С учетом выявленных особенностей разработаны требования к системе компетенций для участников команд инновационных проектов МИП, а также сформулированы основные принципы разработки для соблюдения этих требований.

Ключевые слова: система компетенций, модель компетенций, инновационный проект, управление проектом, руководитель проекта, малое инновационное предприятие

Актуальность и цель работы. В условиях стремительной цифровизации всех областей человеческой деятельности, ускорения процессов создания новых знаний и появления новых технологических решений, профессиональное управление инновационной деятельностью предприятия становится ключевым фактором его успеха в конкурентной борьбе.

Значительно возрастает роль руководителей инновационных проектов, обладающих навыками и компетенциями, необходимыми для адекватного ответа современным вызовам внешней среды. В связи с этим, идентификация и разработка моделей таких компетенций является актуальной задачей.

Цель работы - провести анализ моделей компетенций, представленных в современной научной литературе, а также в международных и отечественных стандартах, для оценивания возможности их применения для повышения качества управления проектной деятельностью на малых инновационных предприятиях (далее, МИП). Выбор данной категории хозяйствующих субъектов в качестве объекта исследования обусловлен не только тем, что на них приходится существенная доля инновационных проектов, но и тем, что ввиду характерной для таких предприятий ограниченности ресурсов, последствия ошибок, допущенных в ходе осуществления даже одного проекта, могут иметь для них катастрофические последствия. В связи с этим вопросы выбора руководителей проектов для МИП имеет даже более важное значение, чем для крупных предприятий.

Методы и обзор литературы. В работе были изучены системы компетенций для руководителей проектов, представленные в научной и методической литературе, в том числе 
в отечественных и международных стандартах по управлению проектами. Для выбора руководителей проектов целесообразно использовать наиболее популярный в настоящее время компетентностный подход, поэтому в работе были исследованы модели компетенций, представленные в современной научной литературе, а также международных и национальных стандартах, в том числе:

- модели компетенций для руководителей проектов, представленные как в рамках моделей управления проектами (ИСО 21500 [4]; PRINCE2 [16], [20]; Р2М [19] и др.), так и независимо от них (GPBSPMP [15]; ГОСТ P 52807-2007 [2]; ГОСТ P 53892-2010 [3]; модели, разработанные для конкретных российских предприятий - см., например, [5], [6] и др.);

- модели компетенциий для руководителей инновационных проектов (ICB [17], SWECOM [21] и др.);

- модели компетенций для специалистов любых профессии, т.е., компетенций, необходимых для достижения успеха в любой профессиональной деятельности (метакомпетенций или «компетенций будущего» - cм., например, [1],[12] и др.).

В общем виде, все рассмотренные модели компетенций включают перечень компетенций или кластеров (групп, областей) компетенций, их элементы и индикаторы. Для моделей, представленных в стандартах, как правило, характерно также наличие уровней сертификации, то есть градации специалистов по управлению проектами в соответствии с уровнями владения определенными наборами компетенций (см., например, [17], [19] и др.).

Основные же отличия рассмотренных моделей лежат в области определения ключевых терминов («компетенция» и «компетентность»); состава компетенций, включаемых в рассмотрение, а также уровня их детализации (количества элементов); индикаторов компетенций и инструментов оценки.

Следует отметить, что в существующих стандартах, как правило, дается определение понятия «компетентность», а не «компетенция», хотя оба термина используются в текстах стандартов как синонимы. Так, International Competence Baseline of the International Project Management Association (ICB IPMA) - международный стандарт, описывающий требования к компетентности менеджеров проектов, определяет «компетентность» как продемонстрированные способности к применению знаний и / или навыков и личностные качества [17].

Стандарты практической компетентности проектных менеджеров категорий GL1 и GL2 («A Framework for Performance Based Competency Standards for Global Level 1 and 2 Project Managers»), разработанные международной инициативой GAPPS, используют понятие компетентности для описания того, «кто достаточно квалифицирован, чтобы выполнить определенную задачу или занять определенную должность» $[15$, p. 1]. Схожую трактовку компетентности содержит и разработанный на его основе ГОСТ Р 52807-2007, в котором предлагается использовать данный термин для «признания того, что специалист обладает достаточными профессиональными знаниями и навыками для выполнения поставленной задачи или исполнения определенных обязанностей» [2, с. 2]

В отличие от нормативных документов, для научных публикаций, как правило, характерно разграничение понятий «компетенция» и «компетентность». При этом, несмотря на значительное многообразие определений данных терминов, представленных в современной научной литературе (см., обзоры существующих определений в [5] - [7], [11], [13] и др.), большинство исследователей сходится в представлении о характере их соотношения. Так, «компетентность», практически всегда рассматривается как признание того, что личность обладает необходимыми «компетенциями» и способностью их применять для решения поставленных задач или исполнения обязанностей.

На основании результатов проведенного исследования определений понятий «компетенция» и «компетентность», представленных в современной научной литературе и нормативных документах, предложены следующие определения указанных понятий:

- компетенции - характеристики личности, которые важны для успешного выполнения проектов и которые могут быть измерены через наблюдаемое поведение;

- компетентность - это наблюдаемое (объективно подтвержденное) соответствие компетенциям.

Как уже было отмечено ранее, помимо отсутствия терминологического единства для существующих моделей компетенций характерны существенные отличия в составе и уровне детализации компетенций, включаемых в рассмотрение. Так, например, модель компетенций в 
P2М [19] состоит из 10 элементов, в ICВ (IPMA) из 46 элементов, подразделенных на 3 группы: технические компетенции (20 элементов), поведенческие элементы (15 элементов), контекстуальные компетенции (11 элементов) [17].

Подобное отсутствие единства при определении состава и содержания компетенций, включаемых в рассмотрение, характерно не только для моделей компетенций руководителей проектов, но и для моделей метакомпетенций или, так называемых, «компетенций будущего». Так, Институт образования при НИУ ВШЭ, основываясь на определении инновационных умений, представленных в рамочной модели «Партнерство по навыкам XXI века» («Partnership for 21st Century Learning») [18], предлагает «Модель компетенций XXI века»:

- Критическое мышление: анализ; вывод и аргументация.

- Креативность: любознательность и воображение.

- Коммуникация и кооперация: анализ и оценка взаимодействия; командная работа; диалог" [12].

П.Безручко, Ю.Шатров, М.Максимова в рамках исследования вопроса практической полезности моделей «компетенций будущего», провели кластерный анализ компетенций, представленных в 8 публикациях авторитетных организаций и сформировали обобщенный перечень таких компетенций:

1. Взаимодействие и сотрудничество с людьми.

2. Мышление и решение проблем.

3. Обучаемость и открытость новому.

4. Инновационность и креативность.

5. Цифровые знания и навыки.

6. Осознанность и управление собой.

7. Междисциплинарное и межкультурное взаимодействие.

8. Управление (людьми, проектами, процессами, ресурсами).

9. Этичность и социальная ответственность.

10. Ориентация на достижение результата [1].

В то же время указанные авторы отмечают, что для выявления качеств, необходимых успеха на конкретном рабочем месте, требуется знание его характеристик и задач. О том, что каждой организации необходимо пройти процесс разработки собственной модели компетенции, утверждает и Н.В. Калюжная [7]. Как и другие авторы, она также отмечает высокую сложность и трудоемкость процесса разработки модели компетенций.

Результаты. Особенности малых инновационных предприятий с точки зрения управления проектами. Для малого инновационного предприятия, которое, как правило, функционирует в условиях острой нехватки ключевых ресурсов, самостоятельная разработка системы компетенций представляется практически невозможной. В связи с этим, для этой категории предприятий представляется целесообразным, не разрабатывать такую систему «с нуля», а адаптировать эталонные модели, представленные в научной литературе и нормативных документах, стремясь при этом к разработке максимально простой модели, позволяющей решить задачи конкретного предприятия.

Для решения указанной задачи необходимо выявить ключевые особенности управления проектами на МИП. Малые инновационные предприятия одновременно обладают признаками и малых, и инновационных предприятий. Эти особенности оказывают существенное влияние на содержание проектной деятельности именно на МИП. В связи с этим были выявлены особенности управления проектами на МИП, как по сравнению с традиционными (неинновационными) предприятиями, так и с крупными инновационными предприятиями.

Так, для малых инновационных предприятий характерны следующие особенности управления проектами по сравнению с традиционными предприятиями:

о значительно большее количество проектов, содержащих инновационную составляющую;

о большая сложность продукции и управления проектами.

По сравнению с крупными предприятиями МИП свойственны следующие особенности:

- возможность отделения инновационной деятельности от операционной деятельности, рекомендуемая различными исследователями, существует только на уровне ролей (временных обязанностей), а не должностных позиций (постоянных обязанностей) или конкретных сотрудников, занимающих эти должности;

\footnotetext{
* Коммуникация и кооперация объединены в один блок, поскольку коммуникация и кооперация встречаются вместе в ситуации взаимодействия и разделение этих компетенций в ситуации оценки является нецелесообразным.
} 
- многочисленность и отсутствие четкого разграничения обязанностей сотрудников, которая проявляется в невыраженности проектных ролей и их смешении (в частности, в совмещении ролей исполнителей и руководителей проекта; в возложении обязанностей по продвижению продукции МИП на исполнителей и руководителей проекта);

- субъективность при назначении руководителей проектов;

- ограниченность ресурсов, в том числе времени руководителей и сотрудников, затрачиваемого на разработку системы компетенций.

Требования к системе компетенций для мальх инновационных предприятий и принциипы их разработки. С учетом выявленных особенностей были разработаны основные требования к системе компетенций для участников проектных команд малых инновационных предприятий (см. табл. 1).

Для соблюдения указанных требований были сформулированы следующие основные принципы разработки модели компетенций:

- Принции открытости. Предоставление сотрудникам полной информации о том, как и для чего на предприятии разрабатываются модели компетенций.

- Принцип вовлеченности. Привлечение к разработке модели сотрудников, которые будут использовать эту модель.

- Принциип соответствия. Стандарты поведения, определяемые моделью компетенций, должны быть применимы для большинства (а лучше - всех) сотрудников предприятия, подходили всем пользователям, а также согласовывались с целями и корпоративными ценностями предприятия.
Возможности использования результатов. Авторам представляется, что выявленная специфика МИП однозначно указывает на необходимость существенной адаптации существующих эталонных моделей компетенций путем их упрощения (см. также результаты исследования в [22]). Дальнейшие исследования целесообразно осуществлять в следующих направлениях:

- Уточнение терминологии для разграничения различных видов компетенций, например, понятий «метакомпетенции», «универсальные», «общепрофессиональные», «надпрофессиональные» компетенции, «кластеры компетенций» и т.п.

- Разработки структуры и выявление минимально необходимого «ядра компетенций» или, скорее, нескольких «ядер» для решения различных задач различных категорий предприятий.

- Выбор, адаптация или разработка методов оценивания характеристик работников предприятий на их соответствие необходимым компетенциям.

Выводы. В статье обоснована необходимость разработки системы компетенций для участников команд инновационных проектов МИП, учитывающей особенности осуществления проектной деятельности именно этой категории предприятий. Использование разработанных требований и сформулированных принципов, позволит МИП существенно упростить процесс разработки системы компетенций и позволит реально использовать компетентностный подход для повышения качество отбора и назначения руководителей проектов, а следовательно, и для повышения результативности и эффективности осуществляемых проектов.

Таблица 1.

\begin{tabular}{|l|l|}
\hline \multicolumn{1}{|c|}{ Требования } & \multicolumn{1}{|c|}{ Формулировки требований } \\
\hline 1. Целостность и полнота & $\begin{array}{l}\text { Модель должна охватывать все этапы ЖЦ инновационного проекта и завер- } \\
\text { шаться разработкой стратегии коммерциализации результатов, полученных } \\
\text { при его выполнении [14] }\end{array}$ \\
\hline 2. Ясность и простота & $\begin{array}{l}\text { Модель должна иметь простую структуру, быть описана простым языком и ее } \\
\text { описание должно исключать возможность двусмысленного толкования }\end{array}$ \\
\hline $\begin{array}{l}\text { 3. Универсальность: } \\
\text { приятия }\end{array}$ & Модель должна быть применима для большинства работников предприятия \\
\hline $\begin{array}{l}\text { 3.2. для проектов предпри- } \\
\text { ятия }\end{array}$ & $\begin{array}{l}\text { Модель должна быть применима для всех проектов предприятия, вне зави- } \\
\text { симости от их уровня сложности. }\end{array}$ \\
\hline $\begin{array}{l}\text { 4. Инвариантность к изме- } \\
\text { няющимся условиям }\end{array}$ & $\begin{array}{l}\text { Базовые элементы модели должны быть неизменными, быть не чувствитель- } \\
\text { ными к изменениям внешней среды, технологий и т.п. [9] }\end{array}$ \\
\hline 5. Объективность & $\begin{array}{l}\text { Модель должна минимизировать субъективизм при принятии решений о } \\
\text { назначении в проектные роли }\end{array}$ \\
\hline
\end{tabular}




\section{Библиографический список}

1. Безручко П. Компетенции неясного будущего [электронный ресурс] / П. Безручко, Ю. Шатров, М. Максимова // Электронное периодическое издание «Harvard Business Review Россия».- URL.: https://hbr-russia.ru/ karera/professionalnyy-i-lichnostnyy-rost/p26131 (дата обращения: 18.03.2021)

2. ГОСТ Р 52807-2007. Руководство по оценке компетентности менеджеров проектов. Национальный стандарт РФ.-М.: Стандартинформ, 2010.-18с

3. ГОСТ Р 53892-2010 Руководство по оценке компетентности менеджеров проектов. Области компетентности и критерии профессионального соответствия. Национальный стандарт РФ.- М.: Стандартинформ, 2011.- 20c.

4. ГОСТ Р ИСО 21500-2014 Руководство по проектному менеджменту. Национальный стандарт РФ.- М.: Стандартинформ, 2015.- 52с

5. Демченкова С.А. Основные подходы к трактовке понятий «компетенция» и «компетентность» за рубежом и их содержательное наполнение // Вестник ТГПУ. 2011. № 13 (115). С. 243-246

6. Дзюбенко И.А. Сущность понятий «компетентность» и «компетенция» // Азимут научных исследований: педагогика и психология. 2013. № 1. С. 18-20

7. Калюжная Н.В. Разработка модели компетенций организации [электронный ресурс] // Молодой ученый. 2016. № 6 (110). C. 447-455._- URL: https://moluch.ru/archive/110/27084/ (дата обращения:18.03.2021)

8. Клименко О. Создание ключевых компетенций руководителей проектов в компании [электронный ресурс] / Электронная библиотека управления интернет-проекта «Корпоративный менеджмент»: статья из журнала «Финансовый директор». 2007. № 9._- URL.: https://www.cfin.ru/management/people/project_competence. shtml (дата обращения: 18.03.2021)

9. Митрофанова Е. Формирование модели компетенций: методический подход // Кадровик. Кадровый менеджмент. 2011. № 8. С. 26-41

10. Мишурова И.В. Методы выявления ключевых компетенций и построения компетентностного профиля руководителя проектов // Естественно-гуманитарные исследования. 2020. № 28 (1). С. 189-196

11. Нигматзянова Г.Х. Сущность понятий «компетенция» и «компетентность» [Электронный ресурс] // Современные научные исследования и инновации. 2013. № 11.- URL: http://web.snauka.ru/issues/2013/11/28698 (дата обращения:18.03.2021).

12. Операционная модель (мониторингового оценивания компетенций $4 \mathrm{~K})$ / Проект Института образования НИУ «Высшая школа экономики».— URL.: https://ioe.hse.ru/monitoring/4k/monitoring/teormodel (дата обращения: 18.03.2021)

13. Смородинова M.В. Многообразие подходов к определению понятий «компетентность» и «компетенция» [электронный ресурс] // Актуальные вопросы современной педагогики: материалы IV Междунар. науч. конф. Т. 0. Уфа:2013. С. 16-18.- URL.: https://moluch.ru/conf/ped/archive/97/4390/ (дата обращения: 18.03.2021)

14. Цыбуков С.И. Реализация инжиниринговых проектов на базе научно-производственного консорциума. Пример проекта «Сани»- от идеи до изделия за четыре месяца / С. И.Цыбуков, С. П. Козлова, А. В. Дынина, Е. В. Орлова, Н. А. Пиликов // Инновации № 11 (241), 2018. С.3-7.

15. GAPPS. A Framework for Performance Based Competency Standards for Global Level 1 and 2 Project Managers [электронный ресурс] / Sydney: Global Alliance for Project Performance Standards. 2007. 48 p. - URL.: https:// globalpmstandards.org/wp-content/uploads/2014/12/GAPPS_Project_Manager_v1.1150411_A4.pdf (дата обращения: 18.03.2021)

16. Directing Successful Projects With PRINCE2 ${ }^{\circledR}$ - 2009 Edition, 2012, London, The Stationery Office.

17. Individual Competence Baseline for Project, Programme and Portfolio Management (ICB). Version 4.0 // International Project Management Association [электронный ресурс]. - URL: http://products.ipma.world/wpcontent/uploads/2016/03/IPMA_ICB_4_0_WEB.pdf (дата обращения: 18.03.2021)

18. The Partnership for 21st Century Learning. Framework for 21st Century Learning. 2019. [электронный ресурс].URL.: http://www.battelleforkids.org/networks/p21/frameworks-resources (дата обращения: 18.03.2021)

19. Р2M: A Guidebook of Project and Program Management for Enterprise Innovation. Summary Translation [электронный ресурс] / Project Management Professionals Certification Center. November 2001. (Revision 1. August 2002). - URL.: http://www.pmprofy.ru/files/756/p2m.pdf (дата обращения: 18.03.2021)

20. PRINCE2 ${ }^{\circledR}: 2009$ Manual - Managing Successful Projects With PRINCE2 ${ }^{\circledR}$ - 2009 Edition. London. The Stationery Office (TSO). 2012. 
21. Software Engineering Competency Model (SWECOM). A Project of the IEEE Computer Society. Version 1.0. 2014 IEEE. 168 p. ISBN-10 0-7695-5373-7; ISBN-13 978-0-7695-5373-3. [электронный ресурc] - URL.: https://www. computer.org/volunteering/boards-and-committees/professional-educational-activities/software-engineeringcompetency-model (дата обращения: 18.03.2021)

22. Бурмистров А.Н., Синявина М.П., Рассказова О.А., Александров И.Н. Модели компетенций руководителей инновационных проектов и возможности их использования на промышленных предприятиях // Экономические науки, 2019, № 6 (175), с.107-116 DOI:10.14451/1.175.107 